Acceptance and Commitment Therapy for a Case of

Scrupulosity-Related Obsessive-Compulsive Disorder

Eric B. Lee, M.A.

Clarissa W. Ong, B.A.

Woolee An, M.A.

Michael P. Twohig, Ph.D.

Utah State University

Corresponding Author:

Eric B. Lee

Department of Psychology

Utah State University

2810 Old Main Hill

Logan, UT 84322

eric.lee@usu.edu

(435) 797-8303 


\begin{abstract}
Acceptance and Commitment Therapy (ACT) is a modern form of Cognitive Behavior Therapy (CBT) with growing support for treating obsessive-compulsive disorder (OCD). We present a case wherein a client presented with scrupulosity-related OCD. We briefly review scrupulosity, explain the theory behind ACT, and present a case, the treatment process, and desired outcomes. Exposure and response prevention (ERP) is described from an ACT perspective and discussed as an option for people with OCD who may be reluctant to engage in more traditional forms of ERP.

Keywords: obsessive compulsive disorder, acceptance and commitment therapy, case study, scrupulosity, exposure and response prevention
\end{abstract}


Acceptance and Commitment Therapy for a Case of

Scrupulosity-Related Obsessive-Compulsive Disorder

Scrupulosity is a form of obsessive compulsive disorder characterized by persistent, unwanted, anxiety provoking thoughts that include doubts about religious or moral issues (Abramowitz, D. Huppert, Cohen, Tolin, \& Cahill, 2002). Obsessions might include excessive fear of sinning, offending God, engaging in immoral acts, imperfect religious practice, or blasphemous mental imagery. These are usually accompanied by compulsive behaviors that are intended to reduce or neutralize the distress caused by the obsessive thoughts. Common scrupulosity-related compulsions include: excessive prayer, scripture study, or other religious practice, confession to religious leaders, and over adherence to minor details of religious practice.

Scrupulosity is a relatively common symptom type of OCD with 5 to $33 \%$ of individuals with OCD reporting significant levels of scrupulosity (Miller \& Hedges, 2008) and approximately 5\% reporting scrupulosity as their primary obsession (Foa \& Kozak, 1995). Individuals with scrupulosity tend to have a poorer prognosis and are more likely to be resistant to treatment than other forms of OCD (Alonso et al., 2001; Ferrão et al., 2006). Thus, treatments that include exposure and response prevention while approaching obsessional thinking from a different perspective than traditional cognitive behavior therapy have potential to address the unique qualities of scrupulosity.

\section{Acceptance and Commitment Therapy}

Acceptance and commitment therapy (ACT) is a modern form of cognitive behavior therapy that emphasizes acceptance, mindfulness, and values. The Society of Clinical Psychology (Division 12 of the American Psychological Association) classifies ACT for OCD as 
a treatment with "modest research support" (Society of Clinical Psychology, 2016). This is likely due to lack of clinical trials from independent research laboratories. There have been two randomized trials out of the United State of America (Twohig et al., 2018; Twohig et al., 2010), as well as four trials out of Iran (Baghooli, Dolatshahi, Mohammadkhani, Moshtagh, \& Naziri, 2014; Esfahani, Kjbaf, \& Abedi, 2015; Rohani et al., 2018; Vakili, Gharraee, Habibi, Lavasani, \& Rasoolian, 2014), including work in both countries with children and adolescents (Armstrong, Morrison, \& Twohig, 2013; Barney, Field, Morrison, \& Twohig, 2017; Shabani et al., under review). While multiple single case studies have been completed with ACT and OCD (e.g., Twohig, Hayes, Masuda, 2016) the most pertinent was one with five adults with scrupulosity (Dehlin, Morrison, \& Twohig, 2013). Standardized measures of OCD showed clinical responses from pre to post and follow-up. This included two measures of OCD severity (i.e., Yale-Brown Obsessive Compulsive Scale; [Goodman et al., 1989a; Goodman et al., 1989b] and Obsessive Compulsive Inventory-Revised ; [Foa et al., 2002]) and a measure of scrupulosity severity (i.e., Penn Inventory of Scrupulosity; Abramowitz et al., 2002). So too did self-monitoring of daily compulsions from 25, 5.6, 4.3 at pre, post, and follow-up. Avoidance of valued activities also decreased from $6,0.7$, and 0.5 at pre, post, and follow-up. Thus, extant evidence suggests that ACT is an efficacious treatment for OCD and scrupulosity in particular.

ACT is situated in the field of contextual behavior science, which is based on behavioral principles, including relational frame theory, and a scientific philosophy of functional contextualism (Hayes, Luoma, Bond, Masuda, \& Lillis, 2006). The behavioral principles shape the specific techniques used in the ACT model (the "how"), whereas functional contextualism undergirds all therapeutic endeavors (the "why"). ACT is part of a scientific tradition that emphasizes doing what works rather than doing what seems to work. Thus, evaluating the utility 
of actions with respect to established goals is key. Furthermore, because decades of research have found behavioral principles to be effective means of changing behavior, ACT tends to rely on these principles to meet its goal of shaping human behavior in ways that are consistent with clients' values.

The goal of ACT is to improve psychological flexibility, the act of contacting present experiences openly while pursuing valued directions (Hayes et al., 2006). The specific skills comprising psychological flexibility are acceptance, defusion, present moment awareness, selfas-context, values, and committed action. Acceptance refers to adopting an open and willing stance toward inner experiences (e.g., anxiety, disgust, obsessions). Defusion is the ability to regard inner experiences as they are rather than as their content. For example, recognizing an obsession about harming a loved one as a thought indicates defusion whereas believing the obsession about harm to be equivalent to actual harm indicates fusion. Present moment awareness is contacting the here-and-now rather than ruminating on the past or worrying about the future. Self-as-context entails holding stories about ourselves lightly instead of allowing ourselves to be consumed by unhelpful self-focused narratives. Values are personally and intrinsically meaningful life directions. Committed action is acting consistently with values. Because ACT is a pragmatic therapy, the merit of therapeutic work is always evaluated in terms of progress toward values. Thus, there is not a preordained treatment goal, rather, living a valued life as described by the client will be emphasized. This is important because sometimes a valuesbased life may differ from a goal of reduced diagnostic severity.

Exposure within an ACT framework is about values rather than distress reduction per se. The aim of contacting a feared stimulus is to provide opportunities for clients to practice psychological flexibility so they are able to live more fulfilling lives outside of the therapy room. 
By learning to approach stimuli that previously restricted behavior using skills of acceptance, defusion, focus on the present moment, and self-as-context, clients expand their behavioral repertoire and increase awareness of and control over their ability to select alternative behaviors-particularly ones that are consistent with values.

\section{Case Conceptualization}

Terry (fictional client compromised of multiple past clients) was a single White Christian man in his mid-30s who was referred to an Anxiety Specialty Clinic by his family doctor for obsessions related to scrupulosity. He had obtained a bachelor's degree and was employed. He had suffered from scrupulosity for more than three years, describing his problem as not being able to control his "dirty thoughts."

Terry was a lifelong, devote member of his Christian congregation and reported finding meaning and purpose through his engagement in the religion. However, he also reported feeling great guilt and shame for not living up to the standards that he perceived his church demanded of him. He felt as though his dirty thoughts were "sinful" and not "clean enough" and that he could perhaps overcome his perceived sins through excessive prayer, scripture study, and church attendance. Unfortunately, his feelings of shame and guilt often led to avoidance of these activities as he felt that he was not clean enough to engage in them.

Despite trying anything he could think of to stop his dirty thoughts, Terry continued to struggle with them daily; moreover, he reported that the thoughts were getting stronger over the past year. Additionally, he often found himself "stuck in [his] head," unable to think about anything else and not able to focus on his surroundings. He also worried that he would act on his unwanted thoughts leading to fears of inappropriately touching people or engaging in unwanted sexual behaviors. In order to avoid such situations, he did not get close to people in public spaces 
and limited himself to large social gatherings. Terry also engaged in excessive reassurance seeking from his family and friends to ensure that he had not engaged in any inappropriate behavior.

Terry was initially screened using a structured clinical interview and met full criteria for OCD, and partial criteria for major depressive disorder. He reported occasional suicidal ideation; however, he described this as passive and denied any suicidal intentions or plans. He also denied any legal or illegal drug use.

We considered each of the six ACT processes in the context of Terry's functioning to help develop a treatment plan and specific areas of focus. Terry was extremely unwilling to experience his unwanted inner experiences. This was especially apparent with regard to his relationship with his intrusive thoughts. We would describe this behavior as very low levels of acceptance or willingness. In a similar vein, Terry was highly fused with his intrusive thoughts. He felt that his dirty thoughts were equivalent to actually engaging in the undesired behavior. Moreover, he believed that his thoughts might actually cause him to physically act in unwanted ways. With regard to present moment awareness, Terry had a tendency to get lost in his thoughts and worries and "zone out" from his surroundings. He had difficulty focusing on present interactions and activities that would have been meaningful to him. Terry often conceptualized himself by the content of his thoughts (e.g., "I am a sinner") and had difficulty recognizing that his internal experiences were temporary and that they did not have to define him as a person; therefore, we would identify the process self-as-context as underdeveloped. With regard to values, Terry could readily identify areas of his life that provided him meaning and fulfillment such as his relationships with family, friends, and God, as well as a drive for education in various topics. Despite these strong identifications with values, there was some concern that his behavior 
might have functioned as a means to please the people in these groups. For example, he would describe some behaviors as what he "should" do, rather than what he would want to do without contextual pressure. Finally, Terry's behavior was a bit inconsistent with regard to committed action. He was still engaging in some valued behaviors, such as spending time with family and attending church activities; however, he was slowly avoiding more of these actions or was finding himself overly distracted even when he was physically present.

Overall, Terry was highly psychologically inflexible and experientially avoidant. He was initially very apprehensive to engage in treatment and feared that intentional exposure to his thoughts might be a sin and would only make his symptoms worsen. He had much room for improvement on each of the six ACT processes, which were targeted in treatment.

\section{Treatment}

Treatment consisted of 20 sessions that closely followed an ACT for OCD treatment protocol used in previous research (Twohig et al., 2010; Twohig et al., 2018). that had been customized to for scrupulosity in another study (Dehlin, Morrison, \& Twohig, 2013). The content and exercises that were used during the sessions are displayed in Table 1.

The first 10 sessions of treatment covered each of the six ACT processes. After some initial psychoeducation about OCD and scrupulosity, a technique called creative hopelessness was engaged in. Creative hopelessness is a collaborative functional analysis of the client's behavior. Each of Terry's behavioral strategies to reduce his anxiety and distress were examined for their short- and long-term effectiveness as well as the associated costs that came from engaging in these strategies. Ultimately, this process led Terry to a realization that the numerous strategies he was using to control his distress were not only costly and time consuming, but largely ineffective, especially in the long-term. This was followed by a session exploring the idea 
that Terry's internal events were perhaps not the real problem, rather, the problem came from his attempts to control his internal events. Terry described his problem as recurrent horrible fears and thoughts that were highly against his personal values. He was asked, "what would it be like to stop constantly trying to control these thoughts and find a more functional way to interact with them so that he could follow his values?" Although he stated that he didn't really know what that would look like, he recognized the dead-end path that his control strategies had led him down and was interested in trying something else.

This "something else" — or alternative strategy was then presented to Terry as acceptance or willingness. The word willingness is often used with clients as it tends to describe the intended process without some of the unintended verbal baggage that the word acceptance can carry. Terry was initially resistant to practicing willingness, especially with his more concerning sexual intrusive thoughts. He worried that his thoughts would either overwhelm him or cause him to act in inappropriate ways. He was open to practice willingness with less difficult thoughts and eventually was able to make space for more difficult thoughts without needing to avoid, control, or change them. Once Terry began to more fully understand willingness, other ACT processes were targeted over the next six to seven sessions. Although outlined linearly in the treatment protocol outline, processes are targeted in a functional, flexible manner. Multiple processes were targeted in some sessions, while other sessions largely addressed a single process. Terry's level of psychological flexibility was monitored throughout treatment using the AAQ-II or the AAQ-OC (a measure of psychological flexibility within OCD) and targeted questions in session to assess progress on individual processes. Over the first 10 sessions, Terry's psychological flexibility greatly improved. More importantly, Terry had clarified his values and was better engaging in values-consistent behavior. 
The final 10 sessions of the protocol focused on exposure and response prevention, additional behavioral commitments to engage in values-consistent behavior, review of ACT processes as needed, and termination. Exposure and response prevention from an ACT perspective is similar in many ways to traditional techniques. Terry was still challenged to expose himself to feared stimuli; however, there was a focus on fostering psychological flexibility during the exposure-making space for uncomfortable thoughts, emotions, and sensations, viewing thoughts as simply thoughts, staying present, and making the exercise values-consistent. Additionally, Terry was not asked to rate his subjective units of distress (SUDS) at any time in therapy; rather, he committed to fully engaged in an exposure for a set amount of time (e.g., 20 minutes) and not quit regardless of how difficult it became. This shifted the focus from Terry's symptoms, to his behavior and commitments. Over the course of treatment, Terry learned that his thoughts, emotions, and bodily sensations did not have any real control over his behavior and that he was free to move in values-consistent directions even with the presence of intrusive thoughts or uncomfortable emotions or sensations.

While the final 10 sessions were where the bulk of exposure and response prevention occurred, this technique was used extensively throughout the initial ACT-focused sessions, just not as explicitly. No hierarchy was created and no formal exposures were engaged in during these initial sessions. However, in-session exercises regularly used intrusive thoughts to practice building psychological flexibility. For example, cognitive defusion involved teaching the client to hold their thoughts lightly and see them as nothing more than just thoughts. This included exercises such as looking at thoughts as though they were passengers on a bus. The passengers could scream at the driver, but the driver could choose whether or not to listen to them. This also involved practicing watching thoughts float by on a stream. While this is similar to mindfulness 
exercises, the emphasis of this exercise was to practice noticing thoughts and choosing to buy into them or just watch them pass by. All of these exercises were done with the intention of fostering broad psychological flexibility skills and could be done with OCD-related or nonOCD-related thoughts. Additionally, homework exercises to engage in values-consistent behavior while practicing willingness, defusion, or present moment awareness involved intentional, direct contact with unwanted internal experiences. While, not formal exposures per se, these exercises likely functioned in a similar manner that ultimately led to increased psychological flexibility as well as new learning about approaching rather than avoiding unwanted internal experiences.

\section{Assessment}

Structured Clinical Interview for DSM-5 (SCID-5; First, Williams, Karg, \& Spitzer, 2015). The SCID-5 was used as a diagnostic measure. The SCID-5 is a widely used tool for both psychological and psychiatric diagnosis and has adequate reliability and validity to assess symptom severity dimensions of both current and lifetime psychopathology (Shankman et al., 2018).

Acceptance and Action Questionnaire-II (AAQ-II; Bond et al., 2011). The AAQ-II is a 7-item self-report scale that measures general psychological flexibility. Items are rated on a 7point Likert-type scale, ranging from 1 (never true) to 7 (always true). Higher scores on the AAQ-II indicate greater levels of psychological inflexibility. The AAQ-II has been found to have adequate reliability and validity in multiple studies (Bond et al., 2011).

\section{Acceptance and Action Questionnaire for Obsessions and Compulsions (AAQ-OC;} Jacoby, Abramowitz, Buchholz, Reuman, \& Blakey, 2018). The AAQ-OC 13-item self-report scale based on the AAQ-II but developed to measure psychological flexibility specifically related 
to unwanted intrusive thoughts like those experienced by individuals with OCD. Items are rated on the same scale as the AAQ-II. The AAQ-OC has demonstrated good preliminary psychometric properties (Jacoby et al., 2018).

Penn Inventory of Scrupulosity (PIOS; Abramowitz et al., 2002). The PIOS is a 19item self-report scale that measures religious symptoms of obsessive-compulsive disorder, including fears of God and fears of sin. Items are rated on a 5-point scale ranging from 0 (never) to 4 (constantly). Higher scores indicate greater levels of scrupulosity. The PIOS has been found to have adequate reliability and validity in past studies (Abramowitz et al., 2002).

Yale-Brown Obsessive-Compulsive Scale (Y-BOCS; Goodman et al., 1989a; Goodman et al., 1989b). The Y-BOCS is a 10-item scale that measures global severity of OCD. Items 1-5 measure parameters of obsessions, items 6-10 measure compulsions, such as time, interference, distress, resistance, and degree of control toward obsessions and compulsions. The Y-BOCS has been found to have adequate reliability and validity in past studies (Kim, Dysken, \& Kuskowski, 1990).

Quality of Life Scale (QOLS; Burckhardt, Woods, Schultz, \& Ziebarth, 1989). The QOLS is a 16-item self-report scale that measures several aspects of functional status including, relationships, employment, health, and recreation. Items are rated on a 7-point Likert-type scale that asks how satisfied the respondent is in these areas ranging from 1 (terrible) to 7 (delighted). Higher scores denote greater levels of quality of life. The QOLS has demonstrated adequate reliability and validity in past studies (Burckhardt \& Anderson, 2003).

\section{Treatment Outcomes}

We do not present exact progress scores for Terry as this client is fictional. Instead, we will describe the pattern of outcomes we would like to see using a collection of typical clients 
with scrupulosity. First, we would like to see a notable decrease in Y-BOCS scores. Many recent studies suggest that scores like 24 (indicating severe OCD) at pretreatment, 12 (indicating mild OCD) at posttreatment, and 12 at follow-up would be typical. Many researchers struggle with how to score the questions on obsessions in the Y-BOCS as most treatments are teaching tolerance over thought regulation. ACT likely takes this one step further so we suggest really focusing on "noticing" obsessions over "controlling" when asking those questions in the YBOCS. In terms of other outcome measures, we would also expect notable decreases in scrupulosity type OCD as measured by the PIOS and increases in functioning and quality of life. All measures that have questions about regulation of internal events do not fit as well with ACT, but these two measures have performed well in ACT. It should be noted that quality of life measures can be slow to change.

ACT focuses heavily on process of change and functioning on a daily basis, and only looks at symptom change over the long-run. Therefore, measures like the AAQ-II and the recent AAQ-OC should be given every other week, and key behaviors (compulsions, valued activities) should be tracked on a daily basis. Additionally, a measure of quality of life or valued behavior engagement are useful to ensure that the treatment goals are being achieved. Client change on measures of psychological flexibility, and corresponding behavior change, informs the therapist if things are moving in the correct direction.

\section{Conclusions}

The elements that really stood out from this case was giving the client enough time to practice psychological flexibility prior to engaging in exposure exercises. Terry was quite resistant to even discuss his intrusive thoughts, let alone make behavior changes. But as acceptance, defusion, and a much greater emphasis on values developed he started to gain 
interest in making the changes. Additionally, life changes that were consistent with his values were occurring, making it much more important to him to engage in the behavior change. Without this time building psychological flexibility, we think it would have been unlikely that he would have stayed in therapy or engaged in any behavior change. This alteration is different than many of the exposure trials which move into exposures after about three sessions. A recent study showed that willingness to fully experience unpleasant and unwanted thoughts, emotions, and bodily sensations was a moderator of the effectiveness of exposure therapy (Reid et al., 2017), and the same could have been true with this case: we needed to make sure psychological flexibility was present prior to starting treatment.

This naturally leads to the questions of who a good candidate for ACT might be and when ACT might be considered as a first line treatment for OCD. This is an empirical question that is unfortunately not well understood at this time. In our opinion, psychological flexibility appears to be a good indicator for response to ACT for OCD. Those with low levels of psychological flexibility would be especially good candidates for ACT. Similarly, when a client demonstrates low levels of specific ACT processes, it might make sense to consider some level of ACT in conjunction with traditional ERP. For example, someone without much motivation for treatment might benefit from values work, while someone who is fearful and avoidant of inner experiences during exposures might be able to better engage following acceptance or defusion work. Some types of OCD, such as scrupulosity seem to be especially cognitive in nature and less responsive to restructuring. People that fit this profile might be especially good fits for ACT. Whether ACT should be considered as a first line treatment is another question altogether that would also benefit from further research. On average, ACT appears to produce comparable outcomes as traditional ERP, but there are other things to consider. From an empirically based 
practice perspective, there are likely circumstances where ACT could be the best approach for individuals, such as the currently described case. However, ERP is a relatively straightforward approach that is more easily trained and implemented than ACT and should likely be most clinician's go-to approach. However, if one is familiar with ACT, it is very reasonable to take an ACT plus ERP approach with most clients, especially in cases where psychological flexibility appears to be an important function of the OCD.

While limited, the present case and the small amount of research on this topic indicate the potential for ACT to successfully treat scrupulosity. Ideally, all individuals with OCD would readily and fully engaged in and respond to exposure and response prevention. However, especially with regard to deeply personal and meaningful obsessions like those found in scrupulosity, this is an unreasonable expectation. These individuals might benefit from treatment that targets processes like psychological flexibility that allow for fuller engagement in exposures. Further research is needed that examines these processes and their potential effect on treatment outcomes for those with scrupulosity. 
Table 1. ACT for Scrupulosity: Adopted from Abbreviated Treatment Manual for OCD.

\begin{tabular}{|c|c|c|}
\hline Session & Treatment components & Exercises/content \\
\hline \multirow[t]{4}{*}{1} & Psychoeducation & A brief psychoeducation about scrupulosity \\
\hline & Getting participant on board & $\begin{array}{l}\text { Acknowledgment that treatment can be } \\
\text { uncomfortable }\end{array}$ \\
\hline & Introduction to creative & Examining of short-term and long-term \\
\hline & Homework & Cost and evaluation of control attempts \\
\hline \multirow[t]{4}{*}{2} & Continue with creative & Digging hole and tug-of war metaphors \\
\hline & hopelessness & National anthem metaphor \\
\hline & $\begin{array}{l}\text { Introduce control as the } \\
\text { problem }\end{array}$ & Chinese finger trap metaphor \\
\hline & Homework & Noticing distraction and avoiding strategies \\
\hline \multirow[t]{5}{*}{3} & Review control as the problem & Chocolate cake exercise \\
\hline & & Cost of unwillingness \\
\hline & Acceptance/willingness & Two scales metaphor \\
\hline & Behavioral commitments & If you're not willing to have it, you've got it \\
\hline & Homework & Practice observing one' internal experiences \\
\hline \multirow[t]{8}{*}{$4-6$} & Self-as-context & $\begin{array}{l}\text { Being non-judgmental attitude toward internal } \\
\text { experiences }\end{array}$ \\
\hline & & Chessboard metaphor \\
\hline & & Passengers on the bus metaphor \\
\hline & Cognitive defusion & Lemon, lemon, lemon exercise \\
\hline & & Leaves on a stream \\
\hline & & Learning how to hold painful thoughts lightly \\
\hline & & Reformulating language conventions \\
\hline & Homework & $\begin{array}{l}\text { Practice holding painful thoughts lightly and non- } \\
\text { judgmental attitude toward them }\end{array}$ \\
\hline \multirow[t]{3}{*}{$7-8$} & Mindfulness & Practicing several mindfulness exercises \\
\hline & & Mindfulness eating \\
\hline & Homework & $\begin{array}{l}\text { Daily behavioral engagement: mindfulness } \\
\text { practice }\end{array}$ \\
\hline \multirow[t]{2}{*}{$9-10$} & $\begin{array}{l}\text { Values \& Behavioral } \\
\text { commitment }\end{array}$ & Value clarification VLQ \& Value sorting card \\
\hline & Homework & Values-based behavioral commitment \\
\hline \multirow[t]{7}{*}{$11-18$} & ACT based ERP & Value based ERP \\
\hline & & Create hierarchy of fearful activities \\
\hline & & $\begin{array}{l}\text { Focusing on "what kind of person I want to be" in } \\
\text { various situations, including outside activities }\end{array}$ \\
\hline & & Willing to put himself out to feel uncomfortable \\
\hline & & $\begin{array}{l}\text { Willing to accept uncertainty (no seeking } \\
\text { assurance) }\end{array}$ \\
\hline & & Willing to create meaningful moments \\
\hline & & $\begin{array}{l}\text { Continuing practice to be non-judgmental toward } \\
\text { his internal experiences while doing outside } \\
\text { exposure }\end{array}$ \\
\hline
\end{tabular}




\begin{tabular}{lll} 
19-20 & $\begin{array}{l}\text { Homework } \\
\text { Termination }\end{array}$ & $\begin{array}{l}\text { Daily Behavioral commitment } \\
\text { Review of previous sessions contents } \\
\text { Review of therapy outcome }\end{array}$ \\
\hline
\end{tabular}

Source: Twohig (2010)

Note: $\mathrm{ACT}=$ acceptance and commitment therapy; ERP $=$ exposure response prevention. Most exercised adapted from Hayes, Strosahl, and Wilson (1999). 


\section{References}

Abramowitz, J. S., D. Huppert, J., Cohen, A. B., Tolin, D. F., \& Cahill, S. P. (2002). Religious obsessions and compulsions in a non-clinical sample: the Penn Inventory of Scrupulosity (PIOS). Behaviour Research and Therapy, 40(7), 825-838. doi: 10.1016/S00057967(01)00070-5

Alonso, P., Menchon, J. M., Pifarre, J., Mataix-Cols, D., Torres, L., Salgado, P., \& Vallejo, J. (2001). Long-term follow-up and predictors of clinical outcome in obsessive-compulsive patients treated with serotonin reuptake inhibitors and behavioral therapy. Journal of Clinical Psychiatry, 62(7), 535-540.

Armstrong, A. B., Morrison, K. L., \& Twohig, M. P. (2013). A preliminary investigation of acceptance and commitment therapy for adolescent obsessive-compulsive disorder. Journal of Cognitive Psychotherapy, 27(2), 175-190. doi: 10.1891/0889-8391.27.2.175

Baghooli, H., Dolatshahi, B., Mohammadkhani, P., Moshtagh, N., \& Naziri, G. (2014). Effectiveness of acceptance and commitment therapy in reduction of severity symptoms of patients with obsessive--compulsive disorder. Advances in Environmental Biology, 2519-2525.

Barney, J. Y., Field, C. E., Morrison, K. L., \& Twohig, M. P. (2017). TREATMENT OF PEDIATRIC OBSESSIVE COMPULSIVE DISORDER UTILIZING PARENTFACILITATED ACCEPTANCE AND COMMITMENT THERAPY. Psychology in the Schools, 54(1), 88-100.

Bond, F. W., Hayes, S. C., Baer, R. A., Carpenter, K. M., Guenole, N., Orcutt, H. K., ... Zettle, R. D. (2011). Preliminary psychometric properties of the Acceptance and Action 
Questionnaire-II: A revised measure of psychological inflexibility and experiential avoidance. Behavior Therapy, 42(4), 676-688. doi: 10.1016/j.beth.2011.03.007

Burckhardt, C. S., \& Anderson, K. L. (2003). The Quality of Life Scale (QOLS): reliability, validity, and utilization. Health and quality of life outcomes, 1(1), 60. doi: 10.1186/1477$7525-1-60$

Burckhardt, C. S., Woods, S. L., Schultz, A. A., \& Ziebarth, D. M. (1989). Quality of life of adults with chronic illness: A psychometric study. Research in Nursing \& Health, 12(6), 347-354. doi: 10.1002/nur.4770120604

Dehlin, J. P., Morrison, K. L., \& Twohig, M. P. (2013). Acceptance and commitment therapy as a treatment for scrupulosity in obsessive compulsive disorder. Behavior Modification, 37(3), 409-430.

Esfahani, M., Kjbaf, M. B., \& Abedi, M. R. (2015). Evaluation and comparison of the effects of time perspective therapy, acceptance and commitment therapy and narrative therapy on severity of symptoms of obsessive-compulsive disorder. Journal of the Indian Academy of Applied Psychology, 41(3), 148.

Ferrão, Y. A., Shavitt, R. G., Bedin, N. R., de Mathis, M. E., Carlos Lopes, A., Fontenelle, L. F., .. . Miguel, E. C. (2006). Clinical features associated to refractory obsessivecompulsive disorder. Journal of Affective Disorders, 94(1-3), 199-209. doi: 10.1016/j.jad.2006.04.019

First, M., Williams, J., Karg, R., \& Spitzer, R. (2015). Structured clinical interview for DSM-5Research version (SCID-5 for DSM-5, research version; SCID-5-RV). Arlington, VA: American Psychiatric Association. 
Foa, E. B., Huppert, J. D., Leiberg, S., Langner, R., Kichic, R., Hajcak, G., \& Salkovskis, P. M. (2002). The Obsessive-Compulsive Inventory: Development and validation of a short version. Psychological Assessment, 14(4), 485-496. doi: 10.1037/1040-3590.14.4.485

Foa, E. B., \& Kozak, M. J. (1995). DSM-IV field trial: Obsessive-compulsive disorder. The American Journal of Psychiatry, 152(1), 90.

Goodman, W. K., Price, L. H., Rasmussen, S. A., Mazure, C., Delgado, P., Heninger, G. R., \& Charney, D. S. (1989a). The Yale-Brown Obsessive Compulsive Scale: II. Validity. Arch Gen Psychiatry, 46(11), 1012-1016. doi: 10.1001/archpsyc.1989.01810110054008

Goodman, W. K., Price, L. H., Rasmussen, S. A., Mazure, C., Fleischmann, R. L., Hill, C. L., . . Charney, D. S. (1989b). The Yale-Brown Obsessive Compulsive Scale: I. Development, Use, and Reliability. Arch Gen Psychiatry, 46(11), 1006-1011. doi:

10.1001/archpsyc. 1989.01810110048007

Hayes, S. C., Luoma, J. B., Bond, F. W., Masuda, A., \& Lillis, J. (2006). Acceptance and commitment therapy: Model, processes and outcomes. Behaviour Research and Therapy, 44(1), 1-25. doi: 10.1016/j.brat.2005.06.006

Jacoby, R. J., Abramowitz, J. S., Buchholz, J., Reuman, L., \& Blakey, S. M. (2018). Experiential Avoidance in the Context of Obsessions: Development and Validation of the Acceptance and Action Questionnaire for Obsessions and Compulsions. Journal of ObsessiveCompulsive and Related Disorders.

Kim, S. W., Dysken, M. W., \& Kuskowski, M. (1990). The Yale-Brown obsessive-compulsive scale: a reliability and validity study. Psychiatry Research, 34(1), 99-106. 
Miller, C. H., \& Hedges, D. W. (2008). Scrupulosity disorder: An overview and introductory analysis. Journal of Anxiety Disorders, 22(6), 1042-1058. doi:

10.1016/j.janxdis.2007.11.004

Reid, A. M., Garner, L. E., Van Kirk, N., Gironda, C., Krompinger, J. W., Brennan, B. P., . . André, M. c. (2017). How willing are you? Willingness as a predictor of change during treatment of adults with obsessive-compulsive disorder. Depression and Anxiety, 34(11), 1057-1064.

Rohani, F., Rasouli-Azad, M., Twohig, M. P., Ghoreishi, F. S., Lee, E. B., \& Akbari, H. (2018). Preliminary test of group acceptance and commitment therapy on obsessive-compulsive disorder for patients on optimal dose of selective serotonin reuptake inhibitors. Journal of Obsessive-Compulsive and Related Disorders, 16, 8-13.

Shankman, S. A., Funkhouser, C. J., Klein, D. N., Davila, J., Lerner, D., \& Hee, D. (2018). Reliability and validity of severity dimensions of psychopathology assessed using the Structured Clinical Interview for DSM-5 (SCID). International Journal of Methods in Psychiatric Research, 27(1), e1590.

Society of Clinical Psychology. (2016). Acceptance and commitment therapy for obsessivecompulsive disorder. Retrieved June 25, 2018, from https://www.div12.org/treatment/acceptance-and-commitment-therapy-for-obsessivecompulsive-disorder/

Twohig, M. P., Abramowitz, J. S., Smith, B. M., Fabricant, L. E., Jacoby, R. J., Morrison, K. L., ... Lederman, T. (2018). Adding acceptance and commitment therapy to exposure and response prevention for obsessive-compulsive disorder: A randomized controlled trial. Behaviour Research and Therapy. 
Twohig, M. P., Hayes, S. C., Plumb, J. C., Pruitt, L. D., Collins, A. B., Hazlett-Stevens, H., \& Woidneck, M. R. (2010). A randomized clinical trial of acceptance and commitment therapy versus progressive relaxation training for obsessive-compulsive disorder. Journal of Consulting and Clinical Psychology, 78(5), 705-716. doi: 10.1037/a0020508

Vakili, Y., Gharraee, B., Habibi, M., Lavasani, F., \& Rasoolian, M. (2014). The Comparison of Acceptance and Commitment Therapy with Selective Serotonin Reuptake Inhibitors in the Treatment of Obsessive-Compulsive Disorder. Zahedan Journal of Research in Medical Sciences, 16(10), 10-14. 